\title{
0 coordenador pedagógico: limites e potencialidades ao atuar na educação básica
}

\author{
Jerônimo Sartori* \\ Lidiane Limana Puiati Pagliarin ${ }^{* *}$
}

\section{Resumo}

O coordenador pedagógico desenvolve papel primordial no ambiente escolar, focando suas práticas diretamente na coordenação do planejamento, do desenvolvimento e da avaliação do processo didático e pedagógico na escola, mobilizando o corpo docente para revisitar criticamente a própria ação pedagógica. Este texto busca refletir sobre como os coordenadores pedagógicos concebem o serviço de coordenação pedagógica no cotidiano da escola, analisando alguns aspectos da formação continuada realizada por meio de um curso de extensão universitária, considerando as relações e inter-relações que se entrecruzam no exercício das funções desse profissional em escolas de educação básica. Nesta análise, considera-se a heterogeneidade da formação inicial dos coordenadores pedagógicos bem como dos espaços em que cada um deles desempenha suas funções. Aborda a diversidade como condição rica e configurada por contextos singulares, trazendo situações que requerem reflexões fundamentadas no diagnóstico de cada lugar. Refere que processo pedagógico abarca as demandas emergentes do espaço educativo, necessitando reconhecer, em sua pluralidade e multidimensionalidade, o potencial para encaminhamentos produzidos pelo diálogo, que considere a reflexão e a crítica na perspectiva da dialética. Todo o processo educativo incorpora trocas sustentadas em redes de sociabilidade, que se conectam pelos interesses políticos e pedagógicos.

Palavras-chave: Ação coordenadora. Coordenador pedagógico. Formação continuada. Prática pedagógica.

Recebido: 02/10/2015 - Aprovado: 03/02/2016

http://dx.doi.org/10.5335/rep.v23i1.6364

Doutor em Educação pela Universidade Federal do Rio Grande do Sul. Professor do curso de Pedagogia e Educação do Campo, Coordenador do PPGPE da Universidade Federal da Fronteira Sul, Campus Erechim. E-mail: jetori55@ yahoo.com.br

** Mestre em Educação pela Universidade Federal de Santa Maria. Professora das disciplinas Didática Geral e Teorias da Aprendizagem e do Desenvolvimento Humano no curso Educação do Campo, da Universidade Federal da Fronteira Sul, Campus Erechim. E-mail: lidiane.puiati@uffs.edu.br 


\section{Introduzindo o foco do estudo}

Pensar em educação e, por extensão, no processo de escolarização básica implica considerar os aspectos socio-históricos que circunscrevem o fenômeno educacional formal. Devido à multiplicidade de interferências que afeta esse campo, detemo-nos a analisar um pequeno, mas significativo, recorte da problemática - a formação continuada de educadores. Nesse sentido, é fundamental repensar a formação continuada em serviço, que historicamente é decidida e pensada em gabinetes dos sistemas de ensino e/ou escolas para serem apenas executadas nas unidades escolares.

O estudo, pois, diz respeito à relevância da formação continuada em serviço, o que aponta para a escola como o locus essencial ao desenvolvimento da reflexão sobre a própria prática pedagógica. Todavia, refletir sobre a própria prática não é algo fácil e tampouco é uma decisão deliberada por parte da maioria dos docentes. Ao coordenador pedagógico cabe o papel de mobilizar o corpo docente a revisitar crítica e reflexivamente sua ação pedagógica, tendo em vista a sua condição de membro orgânico, vinculado diretamente com a coordenação, o planejamento, o desenvolvimento e a avaliação do processo didático e pedagógico na escola.

Portanto, cabe ao coordenador pedagógico fomentar a formação continuada em serviço, privilegiar espaços e tempos para que essa formação aconteça de maneira produtiva, em uma perspectiva de desenvolvimento profissional docente. Desse modo, entendemos que ambos (professores e coordenadores pedagógicos) aprendem, pois ao ensinar também se aprende. Alarcão e Tavares, ao conceber o supervisor como um orientador da prática pedagógica, afirmam que esse deve "criar junto do professor, com o professor e no professor um espírito de investigação-ação" (1987, p. 44).

Como, então, o coordenador pedagógico pode conduzir um processo de análise e de crítica com os docentes da escola? Entendemos que esse exercício não é algo fácil e não se faz sem um mínimo de clareza epistemológica sobre como se ensina e como se aprende. Nesse sentido, o professor precisa, constantemente, reavivar os atos que organiza com o intuito de ensinar ao estudante. Para tanto, o coordenador pedagógico também necessita revigorar, continuamente, seu processo formativo, encharcando-se de novo ânimo, aprimorando seu referencial teórico e, em consequência, sua capacidade crítico-reflexiva.

Destacamos que esta escrita embasa-se nas falas e nos registros realizados no transcurso de três edições do curso de extensão Formação continuada de coordenadores pedagógicos, desenvolvidas em 2012, 2013 e 2014, na Universidade Federal da Fronteira Sul (UFFS), Campus Erechim. Procuramos, nesta reflexão, 
tecer algumas considerações acerca daquilo que envolve a formação continuada dos coordenadores pedagógicos em exercício nas escolas de educação básica. Para isso, tomamos por base as diferentes realidades e as variadas concepções que emergiram das falas e das experiências dos próprios coordenadores pedagógicos em formação.

Ao mesmo tempo em que se propõe a formar, esta proposta de formação continuada dedica-se, também, a tecer um olhar crítico-reflexivo sobre os procedimentos de como é realizada a coordenação pedagógica no cotidiano escolar. Desse modo, este texto centra-se no objetivo de refletir sobre como os coordenadores pedagógicos concebem o serviço de coordenação pedagógica no cotidiano da escola. ${ }^{1} \mathrm{Na}$ sistematização em pauta, consideramos o caráter heterogêneo da formação inicial dos coordenadores pedagógicos bem como dos espaços em que cada um deles desempenha suas funções. Essa diversidade, do mesmo modo que é rica em contextos singulares, traz situações que requerem reflexões críticas e abertas, que devem estar fundamentadas no diagnóstico de cada lugar; ou seja, reflexões construídas em uma dinâmica dialógica e interativa pelo corpus de cada unidade escolar.

É preciso, então, que se estabeleça uma real interpretação acerca do inventário das concepções que os próprios coordenadores pedagógicos portam sobre si mesmos, como profissionais da educação responsáveis pela condução da dinâmica dos "processos pedagógicos" no ambiente escolar. Nesse sentido, pautamos a sistematização dessas ideias iniciais e provisórias, na problematização acerca da falta de conexão entre o que se requer da função e aquilo que, efetivamente, os coordenadores praticam em seu dia a dia. Ou seja, os coordenadores diariamente são amordaçados pelas emergências que se sucedem no cotidiano escolar, representadas na falta de professores, de material didático, de condições adequadas de trabalho, entre outros fatores.

Isso indica que as ausências precarizam o trabalho pedagógico e o próprio processo ensino-aprendizagem, pois, em muitas situações, é preciso improvisar algumas ações para, no mínimo, dar o atendimento necessário ao aluno. É essencial enfatizar que o ato pedagógico não se limita aos processos de ensino e de aprendizagem, ultrapassando o contexto geral em que se insere e se desenvolve a educação formal. A despeito disso, reforçamos que o processo pedagógico abarca as demandas emergentes do ambiente educativo, considerando-se sua pluralidade e sua multidimensionalidade, requerendo do coordenador encaminhamentos dialógicos permanentes, seguidos de análise na perspectiva da dialética. Todo o processo pedagógico, então, incorpora trocas sustentadas em valores simbólicos e em redes de sociabilidade que se conectam pelos interesses políticos e pedagógicos. 


\section{Situando os sujeitos - coordenadores pedagógicos}

Em um estudo que se pretende como descritivo e analítico-crítico, é fundamental que se caracterizem os sujeitos e o contexto investigados. No caso, são sujeitos os coordenadores e são contextos as escolas de educação básica situadas na região de abrangência do Campus Erechim, da UFFS, mais precisamente, inseridas na região norte do Rio Grande do Sul. É preciso, pois, destacar que o corpus deste estudo é situado e datado historicamente em uma cultura em que, ainda, concebe os coordenadores pedagógicos como agentes controladores, fiscalizadores e organizadores de espaços físicos e as escolas como espaços exclusivos destinados ao desenvolvimento do processo ensino-aprendizagem.

É essencial dizer que os coordenadores pedagógicos são educadores das redes municipal e estadual convidados e indicados ao exercício da função de coordenar o processo pedagógico da e na escola. Tais convidados, em sua maioria, são professores efetivos nos quadros funcionais das redes a que pertencem e com formação inicial procedente de diferentes áreas do conhecimento. Uma realidade que demanda formação continuada e em serviço para pensar e construir modos/formas para orientar/assessorar o planejamento e a execução da prática docente em cada instituição de ensino.

No conjunto de coordenadores que acorreram ao curso Formação continuada de coordenadores pedagógicos, nas edições de 2012, 2013 e 2014, os quadros e gráficos a seguir apresentam algumas das características da formação desses agentes educacionais das escolas de educação básica.

Tendo em conta a diversidade no aspecto da formação do quadro dos coordenadores, que configuram o corpus deste estudo (79 coordenadores pedagógicos), é essencial refletir acerca da ação do coordenador pedagógico bem como sobre a necessidade permanente de formação continuada em serviço, centrada no foco da ação coordenadora. É relevante entender que a ação do coordenador pedagógico está enlaçada às condições teórico-práticas, à diversidade formativa e às próprias demandas dos professores, que são os sujeitos primordiais do agir do coordenador pedagógico.

Nesse sentido, Zumpano e Almeida (2012) referem que, por meio da liderança do coordenador pedagógico, é possível envolver os professores em grupos de estudo para refletir coletivamente e produzir conhecimentos que tenham significado especial para o agir docente.

Para a visualização da configuração da formação dos coordenadores, observemos as tabelas e os gráficos que seguem. 
Tabela 1 - Formação - nível médio

\begin{tabular}{l|c}
\hline \multicolumn{1}{c|}{ Curso } & Frequência \\
\hline Auxiliar de Adubação & 01 \\
Análises Clínicas & 03 \\
Auxiliar de Contabilidade & 03 \\
Auxiliar de Processamento de Dados & 02 \\
Auxiliar de Recreação & 02 \\
Desenhista de Arquitetura & 01 \\
Magistério & 42 \\
Preparação para o Trabalho & 19 \\
Técnico em Contabilidade & 03 \\
Técnico em Prótese & 01 \\
Técnico em Redator Auxiliar & 01 \\
Técnico em Secretariado & 01 \\
TOTAL & $\mathbf{7 9}$ \\
\hline
\end{tabular}

Fonte: elaboração dos autores com base nas fichas de inscrição ao curso Formação continuada de coordenadores pedagógicos.

Percebe-se que, embora a grande variedade (doze) de cursos de formação no nível médio, predomina o curso de Magistério, seguido pelo curso de Preparação para o Trabalho.

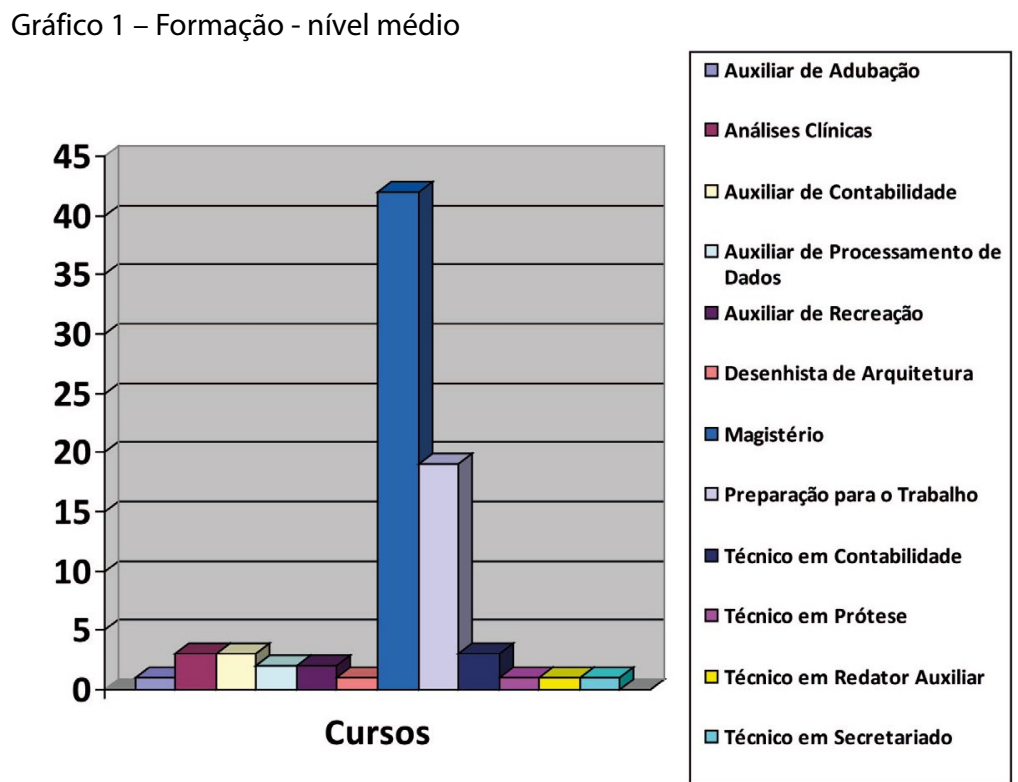

Fonte: elaboração dos autores com base nas fichas de inscrição ao curso Formação continuada de coordenadores pedagógicos. 
A partir dos dados apresentados, fica visível que a maioria dos coordenadores tem sua formação no curso de Magistério em nível médio, o que, de alguma forma, os coloca em vantagem em relação aos demais, haja vista que o referido curso, por meio da prática de estágio, possibilita aos sujeitos uma relação direta com a escola, habilitando professores para atuar na educação infantil e nos anos iniciais da escolarização.

Cabe destacar que isso não quer dizer que os coordenadores com tal formação sejam mais eficientes do que os demais, apenas indica que eles têm um contato, de certa forma, antecipado com a escola, com sua organização e seu funcionamento. Além disso, no curso de Magistério, eles tiveram contato com os conhecimentos pedagógicos, o que os diferencia, de forma positiva, das demais áreas de formação citadas.

Na Tabela 2, apresenta-se os dados referentes ao nível superior de formação desses sujeitos.

Tabela 2 - Formação - graduação nível superior

\begin{tabular}{|c|c|}
\hline Curso & Frequência \\
\hline Artes e Música & 01 \\
\hline Ciências Agrárias & 01 \\
\hline Ciências Biológicas & 12 \\
\hline Geografia & 07 \\
\hline História & 01 \\
\hline Letras & 13 \\
\hline Matemática & 04 \\
\hline Educação Física & 01 \\
\hline Pedagogia & 39 \\
\hline TOTAL & 79 \\
\hline
\end{tabular}

Fonte: elaboração dos autores com base nas fichas de inscrição ao curso Formação continuada de coordenadores pedagógicos.

A Tabela 2, que demonstrou a formação em nível superior dos coordenadores, configurou-se no Gráfico 2. 
Gráfico 2 - Formação - graduação nível superior

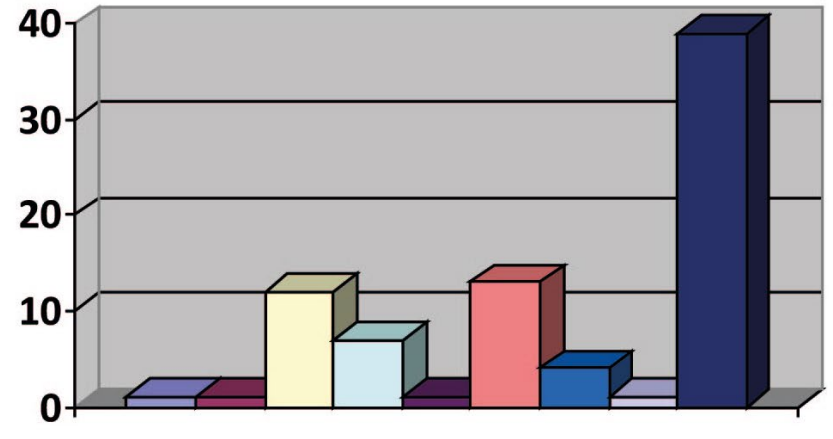

Cursos

\begin{tabular}{|l|}
\hline Artes e Música \\
$\square$ Ciências Agrárias \\
$\square$ Ciências Biológicas \\
$\square$ Geografia \\
$\square$ História \\
$\square$ Letras \\
$\square$ Matemática \\
$\square$ Educação Física \\
$\square$ Pedagogia \\
\hline
\end{tabular}

Fonte: elaboração dos autores com base nas fichas de inscrição ao curso Formação continuada de coordenadores pedagógicos.

Assim, observa-se um número expressivo de coordenadores pedagógicos graduados em Pedagogia. Tal fato revela que esses profissionais têm relativa vantagem em razão de que sua formação foi enriquecida pelos estudos dos fundamentos da educação. O pedagogo leva vantagem em relação às demais licenciaturas, haja vista que, em sua formação acadêmica, aprofunda os conhecimentos acerca dos fundamentos didáticos e pedagógicos essenciais ao exercício da docência. Porém, isso não significa que sua atuação seja melhor ou pior, pois o ato de envolver-se com a ação coordenadora é característica intrínseca a cada professor, especialmente daquele que se predispõe a exercer a função de coordenador pedagógico.

Na sequência, a Tabela 3 apresenta os dados referentes à formação em pós-graduação dos coordenadores. 
Tabela 3 - Formação - pós-graduação lato sensu - especialização

\begin{tabular}{l|c}
\hline \multicolumn{1}{c|}{ Curso } & Frequência \\
\hline Ciência do Movimento & 01 \\
Educação Ambiental & 06 \\
Educação Inclusiva & 03 \\
Educação Infantil e Anos Iniciais & 03 \\
Educação Matemática & 03 \\
Ensino da Língua Inglesa & 01 \\
Espaço, Sociedade e MA & 01 \\
Gestão Educacional & 08 \\
História da Ciência & 01 \\
Interdisciplinaridade & 15 \\
Leitura e Produção Textual & 02 \\
Metodologia do Ensino & 03 \\
Metodologia do Ensino da Língua Portuguesa e Literatura & 02 \\
Orientação Educacional e Supervisão Educacional & 09 \\
Psicopedagogia & 06 \\
Tecnologias na Educação & 01 \\
Técnicas Pedagógicas para a Educação & 13 \\
Sem Especialização & 09 \\
TotaL & 03 \\
\hline
\end{tabular}

Fonte: elaboração dos autores com base nas fichas de inscrição ao curso Formação continuada de coordenadores pedagógicos.

A Tabela 3, registrando a formação em pós-graduação dos sujeitos, configurou o Gráfico 3, a seguir. 
Gráfico 3 - Formação - pós-graduação lato sensu - especialização

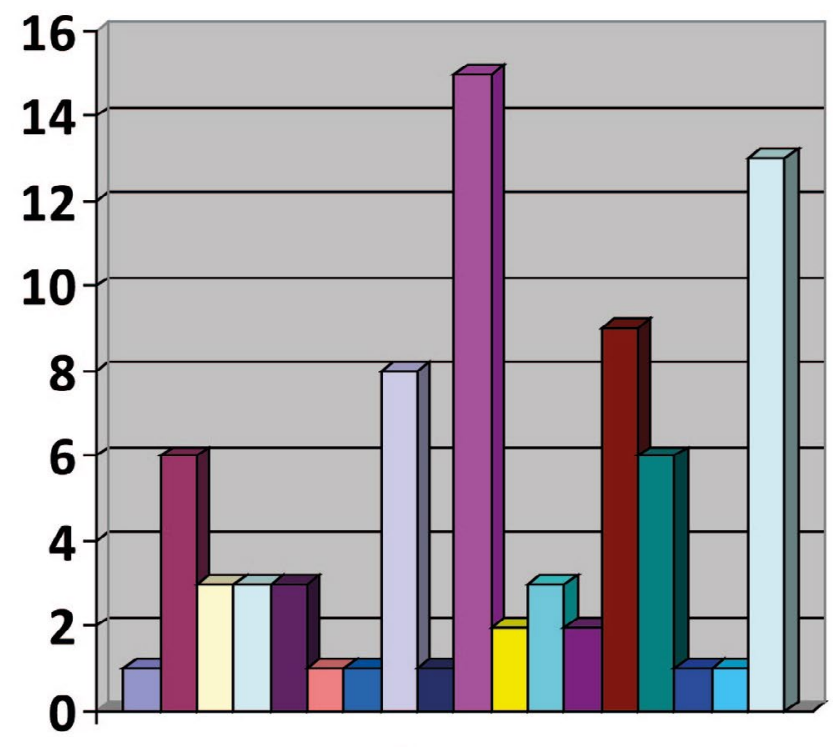

\section{Cursos}

\begin{tabular}{|l|}
\hline$\square$ Ciência do Movimento \\
$\square$ Educação Ambiental \\
$\square$ Educação Inclusiva \\
$\square$ Educação Infantil e Anos Iniciais \\
$\square$ Educação Matemática \\
$\square$ Ensino da Língua Inglesa \\
$\square$ Espaço, Sociedade e MA \\
$\square$ Gestão Educacional \\
$\square$ História da Ciência \\
$\square$ Interdisciplinaridade \\
$\square$ Leitura e Produção Textual \\
$\square$ Metodologia do Ensino \\
$\square$ Metodologia do Ensino da Língua \\
Portuguesa e Literatura \\
Orientação Educacional e Supervisão \\
Educacional \\
$\square$ Tecnologias na Educação \\
$\square$ Sécnicas Pedagógicas para a Educação \\
Especialização
\end{tabular}

Fonte: elaboração dos autores com base nas fichas de inscrição ao curso Formação continuada de coordenadores pedagógicos.

Percebe-se que, no que se refere à formação em curso de pós-graduação lato sensu, há uma grande diversidade em relação ao tipo de curso/formação. Todavia, a ênfase recai em três cursos de especialização, quais sejam: Psicopedagogia, Orientação Educacional e Supervisão Educacional e Gestão Educacional. Vale dizer que esses especialistas, supostamente, podem ter maior vínculo com os quefazeres inerentes à função de coordenar os processos pedagógicos no âmbito da unidade escolar.

Chamamos atenção para o número de coordenadores pedagógicos que não têm especialização: quase $17 \%$ dos participantes. Entendemos que uma pós-graduação abre leques para outras possibilidades de desenvolvimento de seu trabalho cotidiano. Uma pós-graduação que discute sobre as especificidades de um coordenador 
pedagógico poderia auxiliá-los no desempenho de suas funções, ao mesmo tempo em que qualificaria as atividades desenvolvidas na escola como um todo.

Os coordenadores, sujeitos desta pesquisa, atuam em diferentes espaços, isto é, em escolas de educação infantil, de ensino fundamental e de ensino médio, situadas também em diferentes contextos geográficos e sociais (zona rural, centros urbanos e periferias urbanas). É importante destacar que os espaços urbanos, em que se inserem as escolas públicas (municipais e estaduais) dessa região, são caracterizados por municípios de pequeno porte, a maioria deles com populações entre 2.500 a 6.000 habitantes.

Reforçamos, pois, que uma formação acadêmica sólida aos professores-coordenadores é imprescindível, para que possam contextualizar suas práticas escolares, compreender as múltiplas situações que envolvem o cotidiano dos educadores e dos educandos, transformar as queixas do dia a dia da escola em "problemas" que instiguem a invenção de soluções. É fundamental destacar que a formação acadêmica inicial necessita de atualização contínua e sistemática, por meio da formação continuada em serviço; formação que deve acontecer no espaço da escola, considerando o contexto de atuação do professor e os princípios que orientam o projeto educativo da instituição (BENACHIO; PLACCO, 2012).

\section{Ação coordenadora: concepções epistemológicas e teórico-metodológicas}

A reflexão sobre a ação coordenadora precisa acontecer sob a ótica de algum paradigma que auxilie na elaboração de ideias e na construção de uma epistemologia sobre o saber e o fazer do coordenador pedagógico. É preciso entender que um paradigma se configura, em termos gerais, pelo conjunto de ideias, conhecimentos e valores construídos a partir de reflexões acerca das ações efetivadas e analisadas criticamente. Cabe destacar que todo olhar atento, com o intuito de analisar e/ou refletir sobre nossas realizações no cotidiano escolar, pauta-se por uma tendência científica, política e pedagógica. Nesse sentido, é necessário estar vigilante aos acontecimentos para manter-se coerente, na busca de confrontar as práticas através de uma postura crítico-reflexiva, com vistas à superação do habitus ${ }^{2}$ pedagógico que reproduz na escola práticas educativas ditas "tradicionais".

Uma orientação paradigmática pode constituir-se dentro de uma perspectiva pragmatista que se enquadra nas fronteiras de determinada teoria científica; de outro modo, pode originar-se por meio de práticas de intervenção organizadas nos coletivos e com diferentes atores sociais. Nossa posição diante do assumir-se como um coordenador que orienta sua atuação na escola, tendo como norte o planejamento coletivo, é de que o princípio do diálogo é indispensável para agregar 
e estabelecer consensos e compromissos. Nessa perspectiva, as dificuldades que possam se manifestar na escola, envolvendo diretor-coordenador, diretor-professor, coordenador-professor, professor-professor, professor-aluno, aluno-aluno, necessitam mobilizar o grupo, a fim de refletir e rever posições/atitudes para crescer enquanto coletivo.

Refletir acerca do que se entende por "epistemologia" representa um exercício de esclarecimento e desmistificação sobre a ação pedagógica. Uma epistemologia voltada para orientar os processos pedagógicos necessita conduzir a uma postura metodológica diferenciada, no que diz respeito à ação coordenadora no cotidiano escolar. A base para a construção epistemológica reside na prática reflexiva sobre 0 próprio quefazer, principalmente nos espaços que a escola organiza para promover a formação continuada em serviço. A análise/avaliação sistemática da própria prática conduz à construção de novos saberes e aprendizados.

Nesse horizonte, a gestão do processo pedagógico necessita ser perpassada por um processo crítico-reflexivo, envolvendo todos os atores da escola, especialmente os docentes. É imprescindível que na escola o serviço pedagógico seja realizado em parceria com o quadro de professores, primando por ações colaborativas e participativas. A respeito disso, Freire refere que: "Não me faço só, nem faço as coisas só. Faço-me com os outros e com eles faço as coisas” (1995, p. 57).

A ideia de parceria está relacionada ao "fazer com o outro", o que implica comunicação e diálogo franco e aberto entre coordenador e coordenados. O coordenador que assume a postura de mediador toma como ponto de partida e de chegada para suas ações as questões vinculadas ao campo pedagógico, sem desconsiderar questões administrativas e organizacionais da instituição. Contudo, é fundamental reforçar que o propósito principal da atuação do coordenador deve centrar-se na busca da melhoria da qualidade da aprendizagem dos estudantes.

O coordenador pedagógico, nesse sentido, exerce suas funções em dois níveis distintos entre si, porém inter-relacionados: exerce influência direta sobre a aprendizagem e o desenvolvimento profissional do professor e, ao mesmo tempo, exerce influência indireta sobre a aprendizagem e o desenvolvimento dos alunos que esse professor ensina (ALARCÃO; TAVARES, 1987).

$\mathrm{O}$ ato de coordenar a ação pedagógica na escola representa muito mais do que envolver-se com o dinâmico processo de ensinar e aprender, o que envolve relações interpessoais entre coordenador-professor e professor-aluno. Relações que, por sua vez, requerem condições organizacionais que favoreçam a objetivação e o desenvolvimento do ato pedagógico. Sem dúvida, o exercício da coordenação pedagógica traz exigências, apontando para inúmeros desafios, o que implica um olhar atento, uma escuta apurada, firmeza de posições teórico-metodológicas, a persistência, a 
utopia, o devir. Ou seja, o coordenador, longe de ser um "super-homem" ou uma "supermulher", mesmo sujeito a falhas, necessita constituir-se em elo, em construtor e dinamizador de grupo(s), conectando os diferentes setores da sua unidade escolar.

A abertura ao grupo de professores para a manifestação de dúvidas e angústias fortalece a construção da mútua confiança, tão cara entre coordenador e docentes. É imprescindível ao coordenador ter em mente que o corpo docente é constituído por seres humanos singulares, todos na condição de inacabados, mas com potencialidades, qualidades e, também, limites. Nesse processo, é essencial apostar nas potencialidades latentes entre os membros do grupo docente como forma de provocar e motivar o crescimento pessoal e profissional, pois a provocação e a motivação geram ansiedade, angústia, medo, remetendo ao desafio de unir pensamento e ação, de tornar coerente discurso e prática. $\mathrm{O}$ aprendizado, ao lidar com resistências e divergências, é corroborado por Freire ao expressar que: "o eu e o tu passam na dialética das relações constitutivas, dois tu que se fazem eus. [...] há sujeitos que se encontram para a pronúncia do mundo, para a sua transformação" (1987, p. 165-166).

O sentido de "ser coordenador" enlaça-se ao desafio de que suas ações, por não serem neutras, precisam entrecruzar-se com a totalidade da dinâmica escolar, tendo como foco a transformação das práticas escolares, que requerem reconfiguração e ressignificação. Todavia, merece cuidado aquilo que pode configurar-se como prática "pragmatista", haja vista que a ação educativa requer articulação entre compromisso ético e prática pedagógica transformadora. De acordo com Zitkoski, enquanto "[...] seres humanos nos fazemos historicamente éticos, e o ato educativo nunca será neutro diante dessa condição humana no mundo - a de sempre poder decidir, valorar, intervir, romper, enfim, fazer suas próprias escolhas" (2007, p. 26).

Nessa linha de pensamento, realçamos que o discurso corrente no ambiente escolar é o de que o projeto político-pedagógico é o resultado do esforço do coletivo de cada instituição, o que indica que sua elaboração se deu por meio da participação da comunidade escolar. Onde isso efetivamente acontece, a força e o compromisso residem no coletivo, isto é, a responsabilidade é compartilhada, o diálogo é permanente, sendo que "[...] o ponto de partida é a postura crítico-humanizadora do educador, que precisa viver no cotidiano de sua ação docente o desafio de aprender junto com os outros sujeitos envolvidos no processo educativo" (ZITKOSKI, 2007, p. 29).

A postura pedagógica do coordenador é definidora de uma prática pautada pela esperança em relação ao futuro, por isso, é imprescindível a efetivação da prática dialógica entre todos os atores sociais que vivem e convivem no espaço escolar. De acordo com Freire (1987), o diálogo constitui-se em um princípio educativo inerente às ações que buscam tecer um processo educativo crítico e emancipador. 


\section{Discurso e prática no ato de coordenar o processo pedagógico}

$\mathrm{Na}$ atualidade, o espaço escolar é perpassado por incertezas e contradições que tecem as multifaces que compõem a realidade educacional e social. Esse fato, de alguma forma, afeta o locus da educação formal - a escola de educação básica -, que para ser transformada necessita do estranhamento como forma de pensar a construção de uma epistemologia que oriente a prática e o discurso pedagógicos. Nesse processo, é essencial compreender que a educação caracteriza-se como ação prática vinculada aos sujeitos, tanto na dimensão individual quanto coletiva. Por meio da educação, desenvolvem-se os processos cognitivos, afetivos e psicomotores, o que favorece a reconfiguração das relações intersubjetivas e da cosmovisão de homem e de mundo. De acordo com Freire, os sujeitos por meio da práxis criam e recriam culturas e histórias, tendo em conta que a práxis, "[...] sendo reflexão e ação verdadeiramente transformadora da realidade, é fonte de conhecimento reflexivo e criação" (1987, p. 92).

É preciso destacar que existe uma crise sobre o sentido com que a tradição concebe a escola, pois paira, ainda, no meio social e educacional, a afirmativa de que precisamos estudar para "ser alguém na vida". Entretanto, os estudantes expressam desencantamento em relação a tal afirmação, percebendo que tal assertiva não condiz com a realidade. De alguma forma, esse "equívoco" reforça um círculo seletivo e excludente, quando deveria apontar para possíveis fatores de superação. A despeito disso, para superar a ideia de educação domesticadora ainda vigente na escola e entre alguns educadores, Freire afirma que: "Libertar-se de sua força [domesticadora] exige, indiscutivelmente, a emersão dela, a volta sobre ela. É por isso que só através da práxis autêntica que, não sendo 'blábláblá', nem ativismo, mas ação e reflexão, é possível fazê-lo" (1987, p. 38).

Destacamos que à escola, ainda, falta definir um objetivo claramente político, articulado a um projeto que seja assumido social e politicamente por todos os atores que coabitam o contexto escolar. Nesse sentido, é fundamental, pois, dar destaque à ação do coordenador pedagógico, a quem a escola atribui o papel de mobilizar/ liderar o corpo docente para as definições dos elementos básicos que constituem o "projeto educativo" da escola. Para tanto, cabe-nos questionar: como o coordenador pedagógico concebe sua própria função na escola? Quais são as condições objetivas para que o coordenador pedagógico desenvolva suas ações? Não temos a pretensão de dar respostas acabadas, mas de refletir sobre como a função do coordenador pedagógico articula "a concepção de indivíduo assumida pela escola e da relação desse indivíduo com o meio" (BENACHIO; PLACCO, 2012, p. 57). 
Esse campo também se enlaça nas tramas que complexificam a atuação dos profissionais da educação no cotidiano escolar. É preciso, então, considerar que os próprios coordenadores pedagógicos enfrentam dificuldades por não conhecerem as suas reais atribuições no ambiente escolar. Os sujeitos pesquisados, neste estudo, indicam em suas compreensões que a coordenação pedagógica deve "assessorar o professor"; "coordenar o desenvolvimento das atividades pedagógicas"; "preocupar-se com os processos pedagógicos, articulando os atores envolvidos"; "coordenar o trabalho pedagógico da escola, trazendo novos meios e novos horizontes para que todo o trabalho escolar possa lograr êxito"; "organizar e fazer as ligações e comunicações entre os segmentos da escola”, entre outras atividades.

Vários professores que passaram pelo curso de extensão relataram que, ao assumir sua função de coordenador pedagógico, não tinham clareza de suas atribuições, mas que com o passar do tempo foram se identificando melhor com a natureza do trabalho de coordenador. Placco e Souza (2012) afirmam que a identidade do coordenador pedagógico se transforma em um movimento dialético constante, pois suas concepções entram em confronto permanentemente. As autoras afirmam ainda que é frequente a escassa clareza sobre o significado e a estruturação do seu papel bem como sobre suas atribuições e funções. As causas apontadas pelas autoras que justificam essa falta de clareza são: normatização da função há pouco tempo; recentes mudanças nos cursos de graduação que traziam a especificidade desse campo de trabalho; ausência de formação continuada para esse profissional desenvolver habilidades específicas à função.

Verificamos que as indicações fornecidas pelos próprios coordenadores pedagógicos se ajustam àquilo que se estabelece como sendo atribuições desse educador. Contudo, esses mesmos sujeitos - coordenadores pedagógicos - explicitam em suas falas que necessitam "substituir professores", visto que, em algumas escolas, o absenteísmo alcança níveis elevados. Nos comentários entre os coordenadores pedagógicos, também fica evidente que eles atendem pais, encaminham alunos para primeiros socorros na unidade de saúde, atendem a telefonemas, a portaria da escola (recepção), controlam o livro ponto e a carga horária das diferentes disciplinas do currículo escolar. Tais questões indicam que esses profissionais envolvem-se com atividades de cunho técnico e burocrático, realizando ações/atendimentos que fogem à especificidade das atribuições destinadas ao setor pedagógico da escola. Diante disso, podemos realçar que o coordenador pedagógico, na maioria dos casos, ocupa-se e esforça-se na realização de atividades emergenciais no dia a dia da escola (atividades acidentais), deixando para trás as atribuições que são essenciais à função coordenadora. 
Em pesquisa realizada por Placco e Souza (2012), também fica evidente esse excesso de atribuições ao coordenador pedagógico. De acordo com as autoras, isso interfere na construção da sua identidade profissional, pois, ao realizar tarefas que não são de sua função, acabam por incorporá-las como sendo suas e executando-as no dia a dia, sem mais questioná-las. Isso faz com que se instale na escola uma cultura de que tais atividades seriam realmente do coordenador pedagógico, o que acaba sobrecarregando-o.

É preciso destacar que, sem dúvida, aqueles serviços realizados pelo coordenador pedagógico fora do campo de suas atribuições específicas necessitam ser efetivados. Entretanto, entendemos que tais ações/serviços deveriam ou devem ser cumpridos pela escola, mas por outros profissionais da área técnica, administrativa e mesmo pedagógica (no caso da substituição de professores em suas faltas).

Desse modo, as questões referentes aos recursos humanos são da alçada da direção da escola, a qual se envolve diretamente com os aspectos administrativos, tanto com a gestão de recursos humanos como financeiros. À direção cabe, então, reivindicar junto aos órgãos competentes dos diferentes sistemas de ensino (municipal e estadual) a adequação do quadro de recursos humanos para atender dignamente às demandas da escola, sem prejuízo aos serviços essenciais. Nesse caso, o setor pedagógico atua junto aos docentes, mas com o olhar fixo e atento ao processo de ensino-aprendizagem dos educandos, finalidade maior da existência da escola.

$\mathrm{O}$ fato de os coordenadores pedagógicos realizarem ações que fogem da especificidade de sua função na escola aponta alguns desafios a serem enfrentados como forma de fortalecer a sua identidade, bem como de melhorar a dinâmica da prática coordenadora. Entre esses desafios estão elencados: fortalecimento dos estudos entre os professores na escola; melhorar as condições para o desempenho do trabalho do coordenador; mobilizar o grupo de docentes para o trabalho coletivo; clarear o papel e a função do coordenador pedagógico na escola; aprofundar a compreensão sobre a gestão democrática; criar um clima de mútua confiança entre o coordenador e os professores.

Sem dúvida, os aspectos apontados trazem a tônica de que é preciso aprimorar a concepção acerca da função da coordenação pedagógica, contemplando as possibilidades de fortalecimento das forças intraescolares. Para tanto, os próprios coordenadores afirmam que necessitam de formação continuada para compreender as dimensões pessoais e sociais de cada sujeito implicado no processo ensino-aprendizagem. É essencial produzir, a partir da formação continuada em serviço, estratégias que se articulem às necessidades que emergem do e no contexto escolar, de modo a integrar, por meio da prática reflexiva e do trabalho coletivo, formas de intervenção e, consequentemente, de transformação da prática pedagógica. 


\section{Segundo Oliveira:}

O coordenador pedagógico, no desempenho do papel de gestor da formação continuada docente, tem a responsabilidade de elaborar e desenvolver atividades relevantes que mostrem a importância da formação continuada para o docente, pois, o trabalho do professor não se esgota na sala de aula, ele continua nos debates durante as reuniões de horário complementar, na reflexão dos problemas que ocorrem na escola, no planejamento e na avaliação constante do seu trabalho. O professor enfrenta diariamente situações que envolvem a relação entre ele, seus alunos e o conhecimento. [...] problemas que surgem no cotidiano escolar que necessitam de solução imediata ([2015], p. 5-6).

Nesse sentido, entendemos que o coordenador pedagógico necessita continuamente:

[...] rever seu papel, historicamente atribuído, de supervisionar, de deter informações, compartilhando experiências no pensar e no agir com o professor, o que cria possibilidades efetivas de aprenderem juntos, de complementarem o olhar, de alinharem as perspectivas de atuação [...] de forma menos fragmentada e distante das reais necessidades curriculares, pedagógicas e institucionais [...] (ZUMPANO; ALMEIDA, 2012, p. 27).

Destacamos que o discurso e a prática dos coordenadores, para os quais direcionamos nosso olhar e nossa análise, estão imersos em uma realidade escolar complexa, em que se entrecruzam dificuldades, das quais emergem os desafios. Uma realidade perpassada por fragilidades e limitações, no que tange tanto aos recursos humanos como físico-materiais, continua plena de potencialidades e de possibilidades para fazer avançar o processo educacional. É prudente frisar que mudar práticas históricas entranhadas na escola e no ato de "ser professor" não é tarefa fácil, contudo, é necessário que o coordenador tenha "paciência pedagógica", seja persistente em suas utopias e na utopia de melhorar o ensino e a aprendizagem na educação básica.

\section{Refletindo sobre o processo de formação continuada vivenciado}

Embora em caráter provisório, e considerando nossos próprios limites de análise acerca das questões que emergiram no processo vivenciado nas três edições $(2012,2013,2014)$ do curso de extensão Formação continuada de coordenadores pedagógicos, a reflexão considera as concepções que orientam a prática de coordenar os processos pedagógicos nas unidades escolares.

Uma das principais constatações acerca do trabalho do coordenador pedagógico refere-se ao fato de ele dedicar boa parte de seu tempo em realizar as atividades emergentes do dia a dia da escola, agindo como "apagador de incêndio", realizando atividades de cunho meramente técnico e burocrático. Podemos referir que o modo 
de trabalhar a dimensão pedagógica apresenta fragilidades em inter-relacionar as ações do setor pedagógico com a totalidade dos afazeres no cotidiano da escola.

Nessa caminhada, o recorte que fazemos traz elementos que indicam várias concepções sobre a função do coordenador pedagógico, que vão desde práticas centradas em ações burocráticas e técnicas até práticas que se explicitam como protagonismo de um trabalho voltado para a formação continuada do professor. Entendemos que são múltiplos os aspectos que fazem com que o coordenador pedagógico atue desta ou daquela forma, tais como a cultura histórica desse setor na escola, em que as práticas se reproduzem sem a devida crítica e/ou autocrítica.

A formação do coordenador também pode implicar tanto positiva como negativamente, pelo fato de que alguns coordenadores pedagógicos tiveram preterizados, em sua formação, temas que são caros ao serviço de orientar, organizar e conduzir as ações pedagógicas na escola. Também devemos destacar o fato de que alguns coordenadores assumiram a função convidados pela direção, entretanto, não sabiam o papel que deveriam/devem desempenhar, sem a identificação com os quefazeres do campo pedagógico.

Na tentativa de reconstrução epistemológica do serviço de coordenação pedagógica, faz-se necessário investigar atentamente os meios de como se exerce tal função na escola. É indispensável dialogar sobre como se produz sentidos e como se pode ressignificar a ação coordenadora, reaprendendo a observar e considerar a realidade educacional na sua totalidade. Ressaltamos que o serviço de coordenação pedagógica deriva dos serviços realizados pelo especialista em educação denominado supervisor educacional, o qual desenvolvia suas ações em caráter estritamente controlador, fiscalizador e burocrático. Portanto, o histórico da implantação do serviço de coordenação pedagógica, ainda, precisa avançar no que diz respeito a tornar os tempos e espaços escolares democráticos, participativos e colaborativos.

Entre tantos desafios, o estudo aponta a necessidade de consideração ao trabalho pedagógico como uma das possíveis maneiras de comprometer-se com os educandos para que aperfeiçoem o seu processo de apropriação de conhecimento. Entendemos, pois, que o questionamento relativo ao trabalho realizado na escola e na sala de aula representa uma ameaça, sobretudo, quando o docente não compartilha com uma visão crítica de escola, tampouco que o processo ensino-aprendizagem deve ocorrer de forma dialógica, problematizadora, interativa.

Outro aspecto revelado pelos coordenadores pedagógicos refere-se à angústia que os afeta em relação às constantes reclamações dos professores de que os estudantes são desinteressados e indisciplinados. Tais questões são colocadas como inexoráveis, mas sem serem tratadas na escola como questões pedagógicas que merecem o empenho do coletivo de educadores. É preciso, então, decodificar os fatores 
geradores do desinteresse e da indisciplina e tratá-los pedagogicamente, articulados com ações construídas por meio do diálogo e que visem à corresponsabilidade e à copartipação entre todos (professores e alunos). Ressaltamos que o coletivo de professores e gestores pode discutir problemas como esses, constituindo grupos de estudo e discussões na própria escola, de modo a fortalecer e qualificar as práticas pedagógicas desenvolvidas no espaço escolar.

Desse modo, a prática discursiva na escola não pode configurar-se apenas pela denúncia. É preciso desvelar as problemáticas que se entrecruzam no trabalho docente em sala de aula para, na sequência, anunciar propostas que tenham a finalidade de superar as situações-problema. Enfatizamos que a prática que busca superar situações-problema necessita ser perpassada pela problematização e pelo diálogo como princípios pedagógicos. De acordo com Freire: "A educação como prática da liberdade, ao contrário daquela que é prática da dominação, implica a negação do homem abstrato, isolado, solto, desligado do mundo, assim como também a negação do mundo como uma realidade ausente dos homens” (1987, p. 70).

Com base nessas ideias de Freire, entendemos que a atuação do coordenador pedagógico, no âmbito da escola, remete-nos a refletir acerca das multifaces que circunscrevem suas ações e os sujeitos com quem trabalha, considerando que "a formação continuada dos professores" representa a principal função daquele que faz a gestão do processo pedagógico: o coordenador. Entre os relatos evidenciados no processo formativo durante o curso de extensão, torna-se clara a visão dos coordenadores de que é necessário planejar a "ação coordenadora", bem como é preciso investir na prática da reflexão sobre a ação, tanto por parte do coordenador como dos próprios docentes. Para tanto, destacamos, mais uma vez, que é imprescindível estabelecer parcerias embasadas "em princípios de troca de experiências e complementaridade de ações, em que cada um atualiza o que existe em potência no outro, o olhar atento sobre o trabalho executado, a escuta ativa, a apreensão desse profissional completo, [...]" (ZUMPANO; ALMEIDA, 2012, p. 32-33).

Reverberamos sobre quão relevante é para o coordenador pedagógico conhecer o lugar e os sujeitos que interagem e atuam nesse lugar; conhecimento esse necessário para fundamentar e orientar as suas intervenções no dia a dia da unidade escolar. Cabe, portanto, ao coordenador a tarefa de construir relações para que os docentes sintam a confiança no trabalho realizado pelo setor pedagógico, acolhendo a parceria de pensar e agir no coletivo.

Outra necessidade identificada durante o período de formação no curso de extensão refere-se à elaboração e à legitimação de políticas educacionais, em âmbito municipal e estadual, que deem ênfase ao trabalho do coordenador pedagógico. Tais políticas, a nosso ver, devem garantir: que cada escola tenha um coordenador 
pedagógico, pois, na região de abrangência do curso, há prefeituras que dispõem de somente um coordenador para toda a rede de ensino; que esse cargo tenha atribuições claras estabelecidas na legislação, a fim de construir uma identidade a esse profissional; que sejam oportunizados a esse gestor cursos de formação específica para o pleno desenvolvimento de suas funções; que as escolas tenham, de fato, os momentos de formação continuada previstos na sua carga horária, a fim de compartilhar experiências de suas práticas pedagógicas, discutir problemas vivenciados na escola, realizar estudos para qualificar suas práticas, debater propostas pedagógicas, planos de ensino, orientações pedagógicas comuns à escola, bem como realizar avaliações permanentes das práticas desenvolvidas na escola.

Por fim, a análise da prática e da dinâmica do ato de coordenar processos pedagógicos nos permite apontar que a reflexão crítica necessita continuar. Nesse sentido, segundo Oliveira ([2015], p. 17), é fundamental o resgate do trabalho do coordenador pedagógico junto ao coletivo docente, de forma a fortalecer o trabalho pedagógico desenvolvido na escola, adotando estratégias de gestão que revertam em efetivas melhorias no desenvolvimento dos projetos pedagógicos da escola, que resultem em crescimento da aprendizagem e do desempenho dos alunos da escola de educação básica.

\section{Pedagogical coordinator: limits and capability to act on basic education}

\section{Abstract}

The pedagogical coordinator develops leading role in the school environment, focusing their practices directly in the planning, development and evaluation coordination of didactic and pedagogical process at school, mobilizing the teaching staff to revisit critically his own pedagogical action. The text tries to reflect about how the pedagogical coordinators conceive the pedagogical coordination service in the school life, analyzing some aspects of ongoing training conducted through a university extension course, considering the relations and interrelations that interwoven in the exercise of the functions of this professional in schools of basic education. This analysis considers the heterogeneity of initial education of the pedagogical coordinators, as well as the spaces in which each of them performs his/her functions. It discusses the diversity as a rich condition configured for unique contexts, showing situations that require reflections based on the diagnosis of each place. It states that educational process includes the emerging demands of the educational space, recognizing in its plurality and multidimensionality the potential for forwards produced by dialogue, which consider reflection and criticism from the perspective of the dialectic. The entire educational process incorporates sustainable exchanges in social networks that are connected by political and pedagogical interests.

Keywords: Continuing education. Coordinating action. Pedagogical coordinator. Pedagogical practice. 


\section{Notas}

1 Um dos objetivos do projeto de pesquisa O coordenador pedagógico e a formação continuada do professor: limites e possibilidades, aprovado e em desenvolvimento na instituição desde 2013.

2 "[...] um sistema de disposições duráveis e transponíveis que, integrando todas as experiências passadas, funciona a cada momento como uma matriz de percepções, de apreciações e de ações - e torna possível a realização de tarefas infinitamente diferenciadas, graças às transferências analógicas de esquemas [...]" (BOURDIEU, 1983, p. 65, grifo do autor).

\section{Referências}

ALARCÃO, Isabel; TAVARES, José. Supervisão da prática pedagógica: uma perspectiva de desenvolvimento e aprendizagem. Coimbra: Livraria Almedina, 1987.

BENACHIO, Marly das N.; PLACCO, Vera M. N. de S. Desafios para a prática da formação continuada em serviço. In: PLACCO, Vera M. N. de S.; ALMEIDA, Laurinda Ramalho de (Org.). O coordenador pedagógico: provocações e possibilidades de atuação. São Paulo: Edições Loyola, 2012. p. 57-70.

BOURDIEU, Pierre. Sociologia. São Paulo: Ática, 1983.

FREIRE, Paulo. À sombra desta mangabeira. São Paulo: Olho d'água, 1995. . Pedagogia do oprimido. 17. ed. Rio de Janeiro: Paz e Terra, 1987.

OLIVEIRA, Jane Cordeiro de. A função gestora do coordenador pedagógico na formação continuada docente: um estudo nas escolas públicas municipais da cidade do Rio de Janeiro. [2015]. Disponível em: <www.anpae.org.br/.../JaneCordeirodeOliveira-ComunicacaoOral-int.pdf>. Acesso em: 26 nov. 2015.

PLACCO, Vera; SOUZA, Vera. O trabalho do coordenador pedagógico na visão de professores e diretores: contribuições à compreensão de sua identidade profissional. In: PLACCO, Vera M. N. de S.; ALMEIDA, Laurinda Ramalho de (Org.). O coordenador pedagógico: provocações e possibilidades de atuação. São Paulo: Edições Loyola, 2012. p. 9-20.

ZITKOSKI, Jaime José. Saberes da docência : a dialética teoria-prática na perspectiva de Freire. In: SARTORI, Jerônimo; WESCHENFELDER, Lorita Maria (Org.). Práticas pedagógicas: vivências e reflexões. Passo Fundo: UPF Editora, 2007. p. 23-34.

ZUMPANO, Viviani A. A.; ALMEIDA, Laurinda Ramalho de. A atuação do coordenador pedagógico na educação infantil. In: PLACCO, Vera M. N. de S.; ALMEIDA, Laurinda Ramalho de (Org.). $O$ coordenador pedagógico: provocações e possibilidades de atuação. São Paulo: Edições Loyola, 2012. p. 21-36. 